\title{
A evolução da integração regional na América do Sul e a Crise do Mercosul ${ }^{1}$
}

The evolution of regional integration in South America and the Crisis of Mercosul

Marcella Motta ${ }^{2}$

Ariel Martins ${ }^{3}$

Carla Regina da Silva ${ }^{4}$

Ludmila A. Culpi ${ }^{5}$

\section{RESUMO}

O presente boletim tem como objetivo central analisar a construção da integração regional na América do Sul. O problema que se busca responder é como ocorreu o processo de paralisia do MERCOSUL. As conclusões parciais da pesquisa apontam que, embora existam fragilidades graves no processo do MERCOSUL, incluindo o problema da orientação da política externa brasileira, o bloco se mantém. Porém, deve-se revisá-lo em seus objetivos.

Palavras-chave: integração regional, América do Sul, crise do Mercosul.

\section{ABSTRACT}

This newsletter has the central aim to analyze the construction of the regional integration in South America. The problem we are seeking to answer is how the process of paralysis occurred in MERCOSUR. The partial conclusions of the research show that even there are serious weaknesses in the process of MERCOSUR, including the problem of the orientation of Brazilian foreign policy, the block remains. However, the process should be review in its goals.

Key-words: regional integration, South America, Mercosur crisis.

O estudo da integração regional é importante, pois a união entre os países envolve o crescimento e o desenvolvimento econômico, político e social dos países membros (BALASSA, 1961). A investigação da evolução do processo de integração regional na América do Sul no âmbito do MERCOSUL é o objetivo desse boletim. 0

\footnotetext{
${ }^{1}$ Artigo recebido em 3 de setembro de 2013 e aprovado para publicação em 07 de outubro de 2013.

${ }^{2}$ Graduanda em Relações Internacionais no Centro Universitário Internacional UNINTER, Curitiba, Brasil.

${ }^{3}$ Graduando em Relações Internacionais no Centro Universitário Internacional UNINTER, Curitiba, Brasil.

${ }^{4}$ Graduanda em Relações Internacionais no Centro Universitário Internacional UNINTER, Curitiba, Brasil.

${ }^{5}$ Doutoranda em Políticas Públicas, UFPR e Professora do Centro Universitário Internacional UNINTER, Curitiba, Brasil.
} 
projeto integracionista composto por Brasil, Argentina, Paraguai e Uruguai desde 1991 apresentou entraves para progredir. Dessa maneira, é imprescindível estudar a integração regional no MERCOSUL para compreender quais são as dificuldades do avanço nos processos da integração e qual é o status do bloco regional no presente ano de 2013.

A metodologia utilizada no presente artigo baseia-se na análise de documentos, tais como artigos e livros escritos sobre a integração regional e as teorias contemporâneas e sobre o MERCOSUL. A primeira seção pretende verificar historicamente o início do processo da integração, a composição do bloco e também a formação institucional do bloco. A segunda seção visa apresentar os pressupostos centrais das teorias do neofuncionalismo e do intergovernamentalismo e a problemática em sua aplicação ao processo de construção do MERCOSUL. A terceira seção busca desenvolver uma discussão sobre a orientação da política externa brasileira e se, nesse campo, houve uma contribuição para a evolução do processo de integração entre os quatro países. Na última seção serão apresentadas as principais causas da estagnação do processo.

\section{Evolução histórica da Integração}

O MERCOSUL nasceu após o fim de grandes crises impostas por regimes autoritários, tanto no Brasil como na Argentina, implantados por meio de golpes de Estado. Tratava-se de um projeto de integração iniciado pelos dois países, a fim de fortalecer um projeto democrático em uma região historicamente devastada pela ditadura e pelas crises econômicas. 0 bloco do MERCOSUL foi instituído através do tratado de Assunção em 1991, mas adquiriu personalidade jurídica internacional somente com o Protocolo de Ouro Preto, no ano de 1994. O Tratado criou um bloco econômico formado por Brasil, Argentina, Paraguai e Uruguai, com o objetivo central de liberalização comercial. A partir do ano de 2013, a Venezuela passou a fazer parte do bloco em virtude da remoção de Fernando Lugo da presidência do Paraguai, o que provocou a suspensão temporária do país no bloco, tornando possível a adesão da Venezuela como membro pleno do MERCOSUL a partir do dia 31 de julho de 2012, inclusão até então impossível em razão do veto paraguaio (MALAMUD, 2003). 
As iniciativas de integração propostas devem-se às relações bilaterais entre Brasil e Argentina, a fim de utilizar-se de mecanismos eficientes de inserção no mundo globalizado, transformando a região do Cone Sul em um polo de produção e desenvolvimento. Primeiramente, a ideia da integração era mais voltada à infraestrutura e após os anos 2000 o foco voltou-se para o setor econômico e comercial (ALMEIDA, 2011).

Os acordos propostos foram o de livre circulação de bens e serviços, além de uma Tarifa Externa Comum (TEC), que é a padronização de preços dos produtos dos países para exportação. Porém, existe uma Lista de Exceções Nacionais que impede a efetividade dessa tarifa, sob o argumento de proteção de setores sensíveis da economia. Nos primeiros dez anos, não houve muitos avanços no setor de infraestrutura, mas no setor comercial intrarregional os resultados triplicaram, aumentando simultaneamente seus fluxos comerciais extrarregionais, além de expandir o investimento estrangeiro, tornando-se um crescente ator internacional (MALAMUD, 2003).

Outros acordos comuns ao bloco eram a implantação de legislação comum em diversos setores, como fiscal, econômico, comercial e político, livre circulação de pessoas e implantação de uma moeda única e, consequentemente, um Banco Central para o MERCOSUL. Muito pouco foi implementado, pois até a presente data o MERCOSUL não construiu nenhuma estrutura institucional significativa e suas decisões são tomadas mediante mecanismos intergovernamentais, o que requer unanimidade em cada caso. A única organização de tomada de decisão consiste em três órgãos regionais: o Conselho do Mercado Comum (CMC), composto de ministros de Relações Exteriores e da Fazenda de cada país membro, o Grupo do Mercado Comum (GMC) e a Comissão de Comércio. De acordo com Malamud (2003), dois órgãos consultivos (representantes parlamentares e delegados da sociedade civil) e um Secretariado mínimo, localizado em Montevidéu, completam a estrutura institucional.

\section{Contribuição das teorias integracionistas políticas ao processo de integração da América Latina}

As primeiras teorias integracionistas, segundo Oliveira (2002), tiveram ênfase após a Segunda Guerra Mundial e surgiram para explicar o processo de integração 
europeu, o que aponta a dificuldade em aplicá-las à realidade sul-americana. Uma das importantes teorias integracionistas, frequentemente destacada em estudos sobre a integração regional, é a desenvolvida por Bela Balassa, que classifica o processo de integração nas seguintes etapas atingidas ao longo do tempo e a partir de uma série de avanços no processo: área de livre-comércio, união aduaneira, mercado comum, união econômica, integração política e econômica total. Sob a perspectiva dessa teoria, o MERCOSUL pode ser localizado entre a fase de zona livre de comércio e união aduaneira, porém considera-se na literatura que o MERCOSUL pode ser classificado como uma união aduaneira imperfeita, tendo em vista que os Estados muitas vezes não aplicam a Tarifa Externa Comum (TEC), o que é previsto baseado na Lista de Exceções.

Duas teorias que se contrapõem e podem contribuir para a explicação da integração mercosulina são o neofuncionalismo de Haas e intergovernamentalismo defendido, principalmente, por Malamud. 0 neofuncionalismo surgiu como uma crítica à teoria funcionalista e pautava-se, principalmente, na dificuldade de haver 0 trasbordamento por falta de tomada de decisão em relação à integração por parte dos Estados Nacionais. Esse paradigma considera que a integração continuava sendo feita através do processo de incorporação de soberania por parte das instituições supranacionais, mas não dependiam tão só dos interesses dos centros políticos, mas também de setores como as elites e a sociedade civil. Observa-se que o neofuncionalismo não descarta totalmente a ação do Estado nacional, mas o coloca apenas como estimulador dos processos de integração, sendo, então, o viabilizador dessa cooperação e com participação diminuída.

Contrariando a teria neofuncionalista, o intergovernamentalismo defende que o processo de integração depende, sim, da vontade e dos interesses dos Estados membros. Para os estudiosos dessa corrente, a negociação entre Estados a respeito de interesses específicos é o que leva à integração regional. Assim, a dependência mútua é o "cerne" para que a integração ocorra (MALAMUD, 2003).

O intergovernamentalismo da linha liberal estipula que a criação de instituições comunitárias acontece apenas pautada em objetivos específicos dos Estados nacionais e, por estarem sob o controle desses que as criaram, fortalece ainda mais a tomada de decisão desses atores, já que o intergovernamentalismo é contra a supranacionalidade total (LOBO-FERNANDES, 2006). 
É possível afirmar que nenhuma das teorias apresentadas pode explicar, de maneira completa, a integração regional da América Latina. A teoria neofuncionalista explica parcialmente o surgimento do processo de integração europeu e, por isso, não é totalmente adequada para explicar o processo de integração mercosulino, principalmente porque esse processo está longe de instaurar instituições supranacionais. Além disso, no caso do MERCOSUL não se percebe um apoio das elites ao bloco, como defendido pelo neofuncionalismo. Por outro lado, citando a lógica do spill over de Ernest Hass, é inevitável citar o transbordamento nos projetos de cooperação que se iniciaram no âmbito comercial e acabaram direcionados para outras áreas, como educação, saúde, fortalecimento da democracia, infraestrutura, transporte e energia.

Segundo Malamud (2003), observa-se no MERCOSUL um papel extremamente ativo dos governantes dos Estados nacionais na condução da integração, principalmente porque todas as vezes que o processo teve avanço foi a partir de Conferências nas quais estavam reunidos os poderes executivos dos Estados. Desse modo, a teoria intergovernamentalista aparece como a mais adequada para a compreensão do MERCOSUL, já que ela considera que a ação do governo não deve ser excluída, ao contrário, acredita-se que o alto escalão do governo deve participar ativamente.

\section{A orientação da política externa brasileira para a integração: avanços e retrocessos do MERCOSUL}

A compreensão da orientação da política externa brasileira é fundamental para compreender como se ocorreram os avanços e os retrocessos do MERCOSUL. Um dos entraves para o avanço do bloco é o caráter intergovernamental das relações entre os países. 0 progresso da integração regional fluiu até o momento em que os interesses das elites empresariais foram atendidos. A partir de 1990, ocorreu uma transição de valores políticos na maioria dos países do continente americano. Assim, praticamente todos os países da América Latina desprenderam-se de seus governos, que até então eram desenvolvimentistas, baseados nos princípios da CEPAL, para se moldarem ao novo padrão, o do neoliberalismo. Durante esse período, é notável a intervenção do Estado na economia, pois segundo Cervo (2007, p. 218), "as chancelarias" voltavam-se para a questão econômica como uma das suas funções. 
A redemocratização dos países e a hiperinflação da década de 1980 foram fatores internos que contribuíram para que os governos desenvolvimentistas declinassem, permitindo que os moldes do neoliberalismo fossem aceitos pelos países latinoamericanos (CERVO, 2007). Com a globalização, os países do Cone Sul optaram pela integração no âmbito regional para se destacarem no cenário internacional, devido à preocupação de que a concorrência com os demais mercados externos poderia prejudicar sua indústria (VIGEVANI, 2008). Nasce, então, o MERCOSUL em um contexto neoliberal, durante o governo Collor e promovido também pelo Presidente FHC em seu governo. Segundo Cervo (2007), com a mudança de paradigma é possível notar que os governos neoliberais dos países membros do MERCOSUL adotaram medidas avessas quando comparadas ao processo de integração regional europeu. Ao invés de valorizarem a indústria local, abriram o mercado para as multinacionais, que enviavam seus lucros aos países de origem.

A crise econômica de 1999 e a desvalorização do real fizeram com que os produtos brasileiros ficassem mais competitivos para a exportação, porém os produtos argentinos ficaram menos competitivos (CAMARGO, 2006). As necessidades de estruturar a integração regional não foram alimentadas, pois para fazer com que o MERCOSUL avançasse dependia-se essencialmente de ter um nível mais acentuado de institucionalização. No entanto, o Brasil preservou a sua autonomia nas relações com o bloco em detrimento da criação de instituições de caráter supranacional (VIGEVANI, 2008).

As políticas externas dos governos Lula e do governo Dilma aproximam-se mais dos interesses comuns da Argentina no âmbito da cooperação, porém não há grande avanço da integração regional, pois a orientação da política externa brasileira versa para a vertente universalista (VIGEVANI, 2008). E defende-se, ainda, que as elites empresariais, os sindicatos e a sociedade civil organizada exerceram grande influência para a estagnação do MERCOSUL, pois buscam a diversificação de parceiros comerciais. Além disso, a integração regional no MERCOSUL carece de uma redução das assimetrias entre os países, que deveria ser financiada por Brasil e Argentina (CAMARGO, 2006). 


\section{Crise no MERCOSUL}

A literatura sobre a integração sul-americana constata uma paralisia no processo de integração do MERCOSUL, devido a várias razões que serão analisadas na sequência. Conforme analisado ao longo do artigo, o MERCOSUL desenvolveu-se com ênfase na integração comercialista, o que representa um dos pontos de sua fragilidade, pois não houve transferência de soberania para as instituições regionais no âmbito da tomada de decisão em outras áreas políticas. Questiona-se que a funcionalidade do bloco é demonstrada apenas em questões comerciais, e não nas produtivas, o que impede um avanço da integração no âmbito industrial.

De acordo com Camargo (2005), as dificuldades enfrentadas pelo bloco não podem ser atribuídas apenas aos equívocos do MERCOSUL e de seus líderes, pois devese considerar a conjuntura internacional no momento da criação do bloco, a qual promoveu uma expansão das assimetrias entre os Estados e dificultou o aprofundamento do processo. Porém, não se pode ignorar os problemas internos do bloco e a dificuldade de superar as rivalidades e conflitos comerciais entre seus Estados membros. No período atual, o projeto do MERCOSUL precisa ser revisado, especificamente no âmbito institucional, para que haja uma expansão dos objetivos e metas da integração. No final de 1990, o bloco do MERCOSUL demonstrou sinais de fragilidade, desencadeados especialmente pela crise financeira do Brasil que provocou a desvalorização do real em 1999. Assim, além das dificuldades econômicas, outro elemento que provoca a paralisação do processo é a dificuldade de estabelecer uma agenda comum entre os países do bloco (CAMARGO, 2006).

Um dos fatores fundamentais que levam à estagnação do bloco é a não priorização da integração regional pela principal economia da região, como visto na seção anterior. O MERCOSUL é visto pelo Brasil não como um fim em si, mas como um meio para atingir o objetivo mais geral da política externa brasileira, que é a inserção internacional. Assim, o MERCOSUL é entendido como uma plataforma para lançamento do Brasil à posição de potência regional. Nesse sentido, para Vaz (2001), o desafio do Mercosul é vincular as agendas interna e externa do bloco, retomando a funcionalidade da integração e seu dinamismo político.

Segundo Camargo (2006), o desenvolvimento do MERCOSUL depende essencialmente do investimento em infraestrutura e da integração produtiva, o que 
exige maior harmonização macroeconômica como instrumento para a construção de um ator unificado em torno de objetivos políticos comuns, detentor de mais força e poder de barganha nas organizações multilaterais. Porém, isso representa um desafio, pois a coordenação de projetos de desenvolvimento é algo muito distante.

Conforme Vaz (2001), o MERCOSUL distancia-se da formação de um projeto comum de modificação produtiva e estrutural que existia no momento de sua criação, tendo em vista que as questões internas do bloco concentraram-se no comércio, com poucos progressos em outras temáticas. Desse modo, defende-se a necessidade de regresso aos objetivos iniciais e redefinição das instituições para o avanço do processo. Contudo, revela-se uma resistência às alterações institucionais e de objetivos do MERCOSUL.

\section{Considerações Finais}

Defende-se, a partir da análise apresentada, que o MERCOSUL, apesar de seu atual estado de estagnação, continua sendo um instrumento importante para os Estados membros, ainda que seja para servir de proteção econômica ou até mesmo como uma maneira de projetar-se no cenário internacional, que é o caso do Brasil.

Sendo assim, nota-se uma necessidade urgente em encontrar uma solução para os problemas políticos e econômicos que travam o processo. Desse modo, conjuntamente, os Estados devem colaborar para a superação dos entraves que ainda freiam o êxito da integração. Nesse sentido, o MERCOSUL poderá continuar sendo um eixo central nas políticas externas dos países, de modo a expandir para áreas maiores, mas sem deixar o projeto esquecido. Proporcionar um destino de sucesso ao bloco, no qual ele seja reinventado pelos membros, para que ocorra uma integração de fato, atendendo à evolução das relações internacionais e às mudanças internas nos países.

\section{Referências Bibliográficas}

ALMEIDA, Paulo Roberto de. O desenvolvimento do MERCOSUL: progressos e limitações. Revista Espaço da Sophia, parte 1: n. 43, julho-setembro, 2011.

BALA, Bela. Teoria da Integração Econômica. Lisboa: Livraria Clássica, 1964. 
CAMARG0, Sonia. MERCOSUL: crise de crescimento ou crise terminal? Lua Nova, n.68, São Paulo, 2006.

CERVO, Amado. Sob o signo neoliberal: as relações internacionais da América Latina. Revista Brasileira Política Internacional, Brasília, dez, 20000.

LOBO-FERNANDES. Lobo-Fernandes, L. Da integração à Governação Europeia: Portugal, Europeização e o Carácter Multi-Sistêmico da UE, Nação e Defesa, 2006.

MALAMUD, Andrés. "Integração Regional na América Latina: Teorias e Instituições Comparadas" In: ESTEVES, Paulo (ed). Instituições Internacionais Comparadas: segurança, comércio e integração. Belo Horizonte: PUC-MINAS, 2003.

OLIVEIRA, Odete. União Europeia: processos de integração e mutação/ Curitiba: Juruá, 2001.

SARFATI, G. Teorias de Relações Internacionais. São Paulo: Saraiva, 2005.

VAZ, Alcides Costa. MERCOSUL aos dez anos: crise de crescimento ou perda de identidade? Rev. bras. polít. int. vol.44 no.1 Brasília Jan./June, 2001 .

VIGEVANI, Tullo; FAVARON, Gustavo de Mauro; RAMANZINI JUNIOR, Haroldo e CORREIA, Rodrigo Alves. $O$ papel da integração regional para o Brasil: universalismo, soberania e percepção das elites. Rev. bras. polít. int. [online]. 2008, vol.51, n.1, pp. 5-27. 